\title{
On an Abnormal Load Frequency Dependence in Fatigue Endurance of Nitrided Steel*
}

\section{By Kozo ISHIZAKI,** Gianni FIOR*** and Luis CORREDOR****}

\begin{abstract}
Synopsis
The fatigue life vs. frequency in SAE 7140 steel with nitriding treatment was studied, and also compared with the behavior of the same steel without nitriding. An abnormal short fatigue life was observed at load frequencies, lower than about $5 \mathrm{~Hz}$, in nitrided specimens. This behavior may be due to longer relaxation time and enhanced nitrogen diffusion by the Snoek effect at lower frequencies.
\end{abstract}

\section{Introduction}

It is well known that fatigue is one of the most common cause of failures of the components of machines. ${ }^{1)}$ The surface hardness treatment is a conventionally accepted method to improve fatigue endurance for steel components of a machine.

Nitriding is one of the usual industrial methods of the surface treatment. ${ }^{2}$ Although, the nitriding is generally accepted to improve fatigue endurance, ${ }^{2-4}$ ) the load frequency dependence of nitrided steel for fatigue has not been studied.

Considering, for instance, the Snoek effect in a b.c.c. iron, the fatigue endurance of nitrided steel can be easily imagined to depend on the load frequency. The authors intended to seek the effects of the load frequency for nitrided steel.

\section{Experimental Procedure}

Common commercial nitriding steel SAE 7140, Nitralloy steel $135 \mathrm{M}$ with a chemical composition of C $(0.42 w t \%), M n\left(0.43 w t^{0} \%\right)$, Si $(>0.2 w t \%)$, Cr $\left(1.8 \mathrm{wt}^{\mathrm{O}} \%\right)$, Mo $\left(0.26 \mathrm{wt}_{\mathrm{t}}^{\mathrm{O}} \mathrm{o}\right)$, and $\mathrm{Al}(1.2 \mathrm{wt} \%)$, supplied by Inland Steel Co. was chosen for this work.

The fatigue test pieces were machined from bars which had been annealed for $24 \mathrm{~h}$ at $525^{\circ} \mathrm{C}$ in inert atmosphere and furnace cooled.

The gauge length of the specimens was of $16 \mathrm{~mm}$ and diameter $2.5 \mathrm{~mm}$ (A.S.T.M. A370, 1972) and the surface was polished to 500 grid grade emery paper.

These samples were nitrided in a conventional gasnitriding atmosphere, employing pure anhydrous ammonia, at $510^{\circ} \mathrm{C}, 3.5 \mathrm{~h}$ of treatment and $30 \%$ of dissociation rate of the ammonia gas.

The typical results of microhardness tests are shown in Fig. 1, for two different batches of nitriding to verify the nitrided depth. The reproducibility of nitriding was good. The penetration depth was also verified by Auger Electron Spectroscopy (A.E.S.), measuring the intensity of nitrogen peak on spectra taken across the transverse section area. The case hardness depth so found agreed well with the microhardness tests. ${ }^{5}$ )

The typical tensile properties of the steel before and after nitriding are shown in Table 1 .

Fatigue tests were conducted by a closed-loop hydraulic M.T.S. $25 \mathrm{t}$, universal machine, and INSTRON 1322, and the applied load was alternated sinusoidally between tensile load and zero load. The maximum tensile load was chosen to correspond to $90 \%$ of the ultimate tensile strength.

\section{Experimental Results}

Figures 2 and 3 show the life (the number of cycles to failure) of the fatigue tests for annealed steel and nitrided samples respectively, in logarithmic scale.

The fatigue tests were conducted with the maximum tensile load corresponding to the $90 \%$ stress of the ultimate tensile strength, i.e., $880 \mathrm{MPa}(90 \mathrm{~kg} /$ $\left.\mathrm{mm}^{2}\right)$ for annealed samples and $970 \mathrm{MPa}\left(99 \mathrm{~kg} / \mathrm{mm}^{2}\right)$ for nitrided steel. Since the load is different for both cases, we discuss only relative change of the life.

The smooth increase of the life with respect to the increase of the frequency is a normal effect due to relaxation time. Similar effects were observed in aluminum alloys, ${ }^{6-8)}$ as well as steel ${ }^{8,9)}$ and Inconel 718.10) Kaplun ${ }^{11)}$ wrote a review article on this effect.

One should always expect the lower life for the lower frequency. The sample has longer relaxation time and bigger effect on the damage due to the deformation at the lower frequencies. This effect is the result of the smooth increasing life with the increasing frequency for the annealed steel, shown in Fig. 2. On the other hand a sudden change of the fatigue life is clearly noticed for nitrided steel, at the frequency of around $5 \mathrm{~Hz}$, and a minimum point around $1 \mathrm{~Hz}$, (see Fig. 3). The life for frequencies higher than $10 \mathrm{~Hz}$ is about one order of

Table 1. Tensile properties before and after nitriding.

\begin{tabular}{l|ccc}
\hline & $\begin{array}{c}\text { Yield } \\
\text { strength } \\
(\mathrm{MPa})\end{array}$ & $\begin{array}{c}\text { U.T.S. } \\
(\mathrm{MPa})\end{array}$ & $\begin{array}{c}\text { Elongation } \\
(\%)\end{array}$ \\
\hline $\begin{array}{l}\text { As annealed } \\
\left(24 \mathrm{~h} \text { at } 525^{\circ} \mathrm{C}\right)\end{array}$ & 920 & 980 & 14 \\
\hline Nitrided & 1030 & 1080 & 8 \\
\hline
\end{tabular}

* $\quad$ Based in part on M.S. Thesis of L. Corredor to C.E.A., IVIC, Venezuela. Received August 27, 1979.

** Departmento de Ciencia de los Materiales, Universidad Simón Bolívar, Caracas 108, Venezuela.

*** Formerly Universidad Simón Bolívar, Venezuela. Now at Department of Materials Science and Mineral Engineering, University of California, Berkeley, Calif. 94720, U.S.A.

**** Centro de Ingeniería, Instituto Venezolano de Investigaciones Científicas, Caracas, Venezuela. 


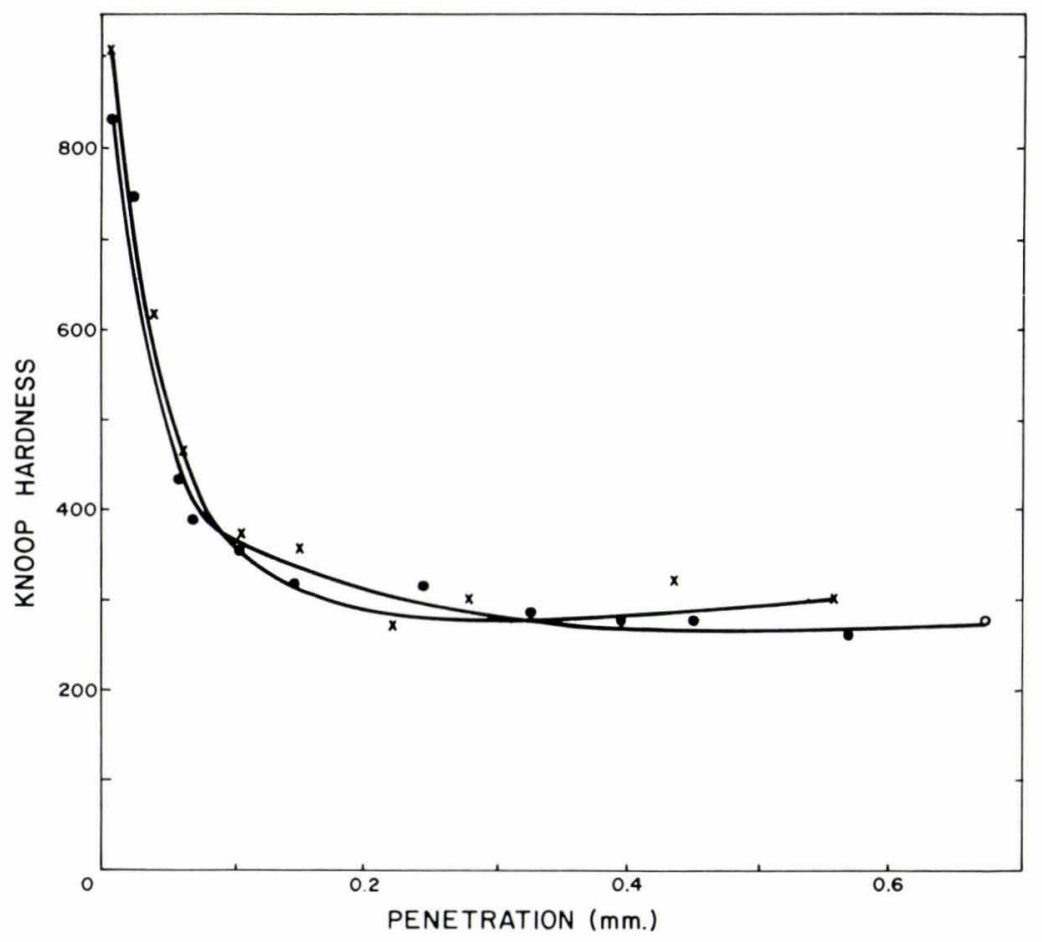

Fig. 1. Microhardness (Knoop $100 \mathrm{~g}$ ) vs, penetration depth for two different batches of nitriding.
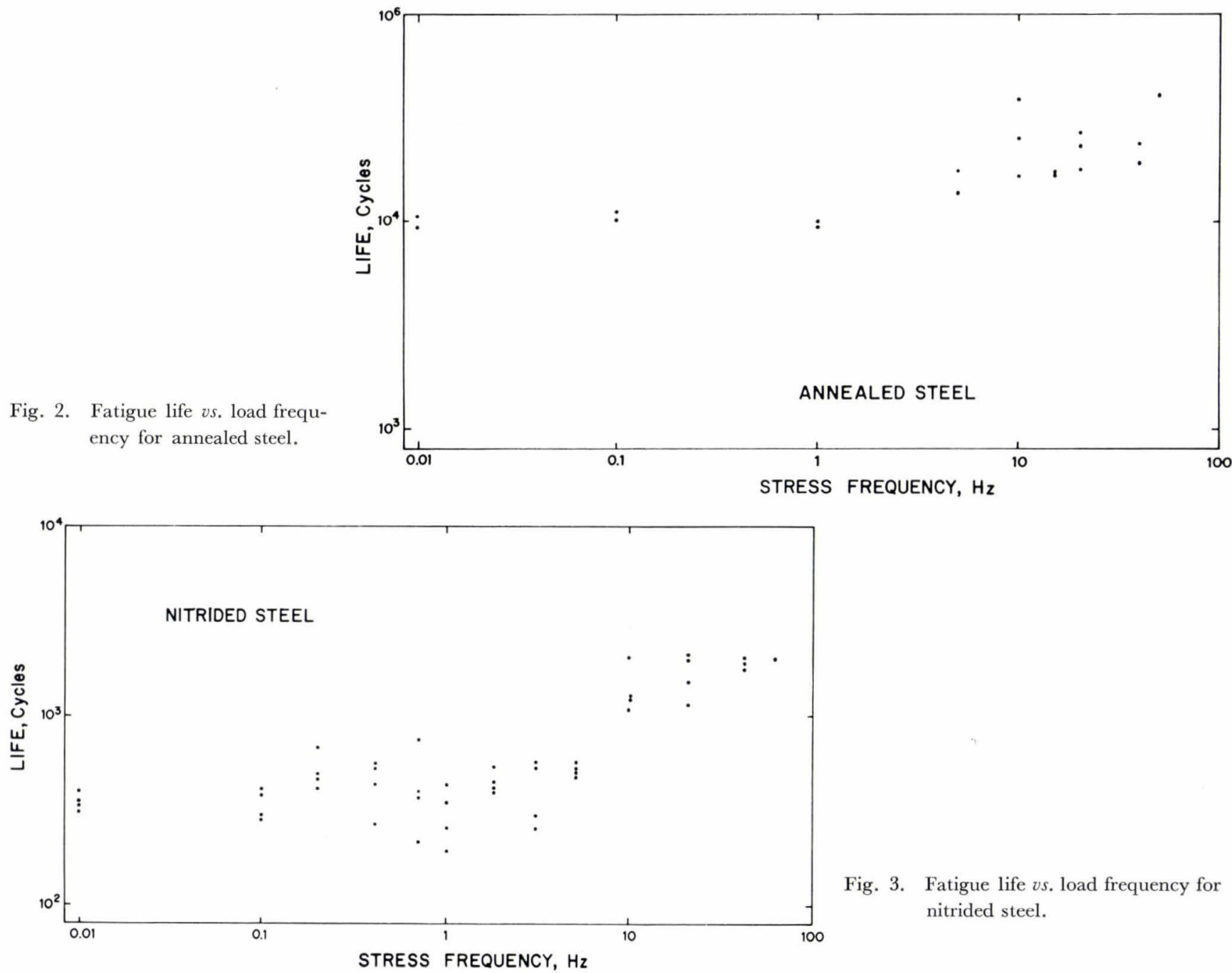

Fig. 3. Fatigue life $v s$. load frequency for nitrided steel.

magnitude higher than the life for frequencies lower than about $5 \mathrm{~Hz}$. This implies an abnormal frequency dependence of nitrided steel.
Jones and Martin ${ }^{12)}$ conducted fatigue tests for a similar steel En 41B, nitrided by plasma, with composition in weight percent: $\mathrm{C}(0.42), \mathrm{Si}(0.38), \mathrm{Mn}$ 
(0.57), Cr (1.56), Mo (0.17), $\mathrm{Ni} \mathrm{(0.19)} \mathrm{and} \mathrm{Al}(1.0)$, to obtain $S-\mathcal{N}$ curves for different case depth of nitriding, but at only one fixed frequency of $40 \mathrm{~Hz} .{ }^{13}$ ) They reported the early surface cracking during tests at high stress level (or low cycle fatigue). Fractographic examination by optical and scanning electron microscope revealed that the case cracking occurred at the early stage of each test in nitrided steel for both cases.

\section{Discussion}

It is well known that the application of a unidirectional stress, to b.c.c. metals would favor the occupation by interstitial atoms of those octahedral sites for which the anisotropical distortion coincided with the overall strain. This phenomenon is the Snoek effect and is particularly strong for carbon and nitrogen interstitial solid solution atoms in alpha-iron.

The frequency of the effect for interstitial nitrogen atoms, that is the jump frequency of nitrogen atoms in alpha-iron at ambient temperature have been reported by various investigators. Among them Polder, ${ }^{14)}$ Nowick et al., ${ }^{15)}$ and Evans and Douthwaite $^{16)}$ reported $3 \mathrm{~Hz}$; moreover, Rosinger, ${ }^{17)}$ Powers and Doyle, ${ }^{18)}$ Smallman, ${ }^{19)}$ Hume-Rothery, ${ }^{20)}$ and Schoeck ${ }^{21)}$ reported frequencies of $\sim 1 \mathrm{~Hz}$.

Considering this effect in nitrided steel, it can be deduced that application of the load frequencies of the same order to that of the nitrogen jump frequency for the Snoek peak must cause nitrogen diffusion induced by cyclic stress. Moreover, solute nitrogen atoms, according to Schoeck and Mondino ${ }^{22)}$ and Cochardt et al. ${ }^{23)}$ can interact with both edge and screw dislocations and in such a region, near the stress field of dislocations, diffuse with larger activation energy than in a dislocation free matrix. Thus, the interstitial nitrogen atoms jump and rearrange in the dislocation stress field and the solid solution becomes ordered around the dislocation line by the cyclic applied stress. This effect must be enhanced at fatigue frequency lower than about $5 \mathrm{~Hz}$ because of the longer relaxation time than the resonant time of the Snoek effect.

The authors imagine that this effect interacts with dislocation cell structure due to cyclic stress, and causes the pronounced effects on fatigue life.

\section{Conclusions}

From the present work we may conclude the followings:
(1) Nitrided steel has abnormal short fatigue life at frequencies lower than about $5 \mathrm{~Hz}$.

(2) Abnormal short fatigue life of nitrided steel may be attributed to longer relaxation time and enhanced nitrogen diffusion.

\section{Acknowledgements}

This work was partially supported by " Centro de Estudios Avanzados (S.E.A.), Instituto Venezolano de Investigaciones Científicas (I.V.I.C.)".

The scanning electron microscope used for this work was supplied by " Consejo Nacional de Investigaciones Científicas y Tecnologicas, (CONICIT)".

\section{REFERENCES}

1) For example, Chapter I of the Proceeding of 1978 ASM, Materials Science Seminar, "Fatigue and Microstructure ", ed. by M. Meshii, ASM, (1978).

2) For example, Source Book on Nitriding, ASM, (1977).

3) H. Sutton: Metal Treatg., 2 (1936), 89.

4) W. E. Bardgett: Metal Treatg., 10 (1943), 87.

5) K. Ishizaki, B. Chornik and L. Corredor: to be published.

6) A. Hartman and J. Shijve: Engineering Fracture Mechanics, 3 (1970), 615.

7) F. J. Bradshaw and C. Wheeler: Intern. J. Fract. Mech., 5 (1969), 255.

8) T. Yokobori and K. Sato: Engineering Fracture Mechanics, 8 (1976), 81.

9) V. P. Rudenko et al.: Soviet Materials Science, 14 (1978), 91.

10) M. Clavel and A. Pineau: Met. Trans., 9A (1978), 471.

11) A. B. Kaplun: Soviet Materials Science, 14 (1979), 387.

12) B. K. Jones and J. W. Martin: Metals Technology, 217 (1978), July.

13) J. W. Martin: Private communication, (1979).

14) D. Polder: Philips Res. Rep., 1 (1945), 5.

15) A. S. Nowick, Fast and Verrijp: Progress in Metal Physics, IV, Pergamon Press, London, (1953), 1-70.

16) J. T. Evans and R. M. Douthwaite: Acta Met., 21 (1973), 49.

17) H. E. Rosinger: Metal Science, 9 (1975), 1.

18) R. W. Powers and Margaret V. Doyle: J. Appl. Phys., 30 (1959), 514.

19) R. E. Smallman: Modern Physical Metallurgy, 2nd Ed., Butterworths, London, (1963), 252.

20) W. Hume-Rothery: The Structures of Alloys of Iron, 1st Ed., Pergamon Press, London, (1966), 43.

21) G. Schoeck: Acta Met., 11 (1963), 617.

22) G. Schoeck and M. Mondino: J. Phys. Soc. Japan, 18 (1964), Suppl. I, 149.

23) A. W. Cochardt, G. Schoeck and H. Wiedersich: Acta Met., 3 (1955), 533. 